\title{
Corrigendum
}

\section{Corrigendum to "Isolation and Molecular Identification and Antimicrobial Susceptibility of Providencia spp. from Raw Cow's Milk in Baghdad, Iraq"}

\author{
Nagham Mohammed Al-Gburi \\ Zoonotic Diseases Unit, College of Veterinary Medicine, University of Baghdad, Baghdad, Iraq \\ Correspondence should be addressed to Nagham Mohammed Al-Gburi; drvet2011@yahoo.com \\ Received 19 January 2021; Accepted 19 January 2021; Published 30 January 2021 \\ Copyright (c) 2021 Nagham Mohammed Al-Gburi. This is an open access article distributed under the Creative Commons \\ Attribution License, which permits unrestricted use, distribution, and reproduction in any medium, provided the original work is \\ properly cited.
}

In the article titled "Isolation and Molecular Identification and Antimicrobial Susceptibility of Providencia spp. from Raw Cow's Milk in Baghdad, Iraq" [1], the name of the author was given incorrectly as Nagham Mohammed Ayyal Al-Gburi. The author's name and affiliation should be corrected as shown above.

Additionally, there was an error in the second sentence of the abstract and the second sentence of the Materials and Methods section, where the word "McConkey" should be corrected to "MacConkey."

\section{References}

[1] N. M. A. Al-Gburi, "Isolation and Molecular Identification and Antimicrobial Susceptibility of Providencia spp. from Raw Cow's Milk in Baghdad, Iraq," Veterinary Medicine International, vol. 2020, Article ID 8874747, 6 pages, 2020. 